Full-Length Article

\title{
Music Therapy for Neuropsychiatric Symptoms in the General Hospital: a systematic literature review
}

\author{
Carol-Anne Sherriff ${ }^{1}$, Jillian Mathews ${ }^{2}$, Emma L. Reynish ${ }^{2}$, Susan D. Shenkin ${ }^{2}$ \\ ${ }^{1}$ Care of the Elderly, NHS Lothian, United Kingdom \\ ${ }^{2}$ Medicine of the Elderly, NHS Lothian, United Kingdom
}

\begin{abstract}
Dementia and delirium are common in medical and surgical inpatients. Neuropsychiatric symptoms can be challenging to manage. Non-pharmacological interventions such as music therapy have been used to manage symptoms in psychiatric hospitals and nursing homes but are not routine in general hospitals. We performed a systematic literature review to establish whether music therapy improves neuropsychiatric symptoms in adults with dementia and/or delirium in the general hospital. We searched CINAHL, Medline and PsycINFO in November 2015. Search terms included music therapy, dementia, delirium. We screened 5054 titles, and read 142 full text articles. None of these met inclusion criteria for our review. To inform future research in music in general hospitals for people with dementia and/or delirium, we qualitatively reviewed 8 articles involving 239 patients. Music delivery was feasible and had a positive effect on some aspects of neuropsychiatric symptoms in various settings, but the studies were generally small, at high risk of bias, and did not use recognized frameworks for evaluating complex interventions. We found no robust published evidence for the use of music therapy in the treatment of neuropsychiatric symptoms in patients with dementia and/or delirium in the general hospital. Well-designed studies of this promising intervention are needed.
\end{abstract}

Keywords: Delirium, dementia, neuropsychiatric symptoms, music therapy, general hospital.

multilingual abstract $\mid$ mmd.iammonline.com

\section{Background}

Dementia and delirium are common in general hospitals, often co-exist, and are associated with poor outcomes for patients [1]. Dementia is a progressive syndrome characterized by a significant cognitive decline that interferes with activities of daily living and can cause behavioral changes. Delirium, also known as acute confusion, is defined by disturbed consciousness, inattention and impaired cognition with an acute onset and fluctuating course, often due to an underlying medical or surgical cause [2]. Neuropsychiatric symptoms (NPS) or behavioral disturbance, such as agitation, apathy, depression and hallucinations can present in both conditions and are distressing for patients and family, and, can present management challenges for medical, nursing and allied health professionals [1].

Non-pharmacological interventions to reduce NPS are preferred over the use of pharmacological methods as first line

\section{PRODUCTION NOTES: Address correspondence to:}

Carol-Anne Sherriff, E-mail: carol-anne.sherriff@nhs.net | COI statement: The authors declared that no financial support was given for the writing of this article. The authors have no conflict of interest to declare. treatment [3]. Music is one potential intervention that may have therapeutic effects $[4,5]$. Music can be provided in a range of ways, which can be considered as a spectrum from passive (listening to the radio, observing live performance) to participatory (singing or playing an instrument). Music therapy (MT) is delivered by a trained therapist who can modify a session from passive listening to active participation in response to an individual's presentation and reactions.

The World Federation of Music Therapy defines MT as "the professional use of music and its elements as an intervention in medical, educational, and everyday environments with individuals, groups, families, or communities who seek to optimize their quality of life and improve their physical, social, communicative, emotional, intellectual, and spiritual health and wellbeing" [6]. Most research into the effects of music has been conducted on behaviour in dementia and other mental illnesses [7], rather than delirium, using recorded or live musicians, not trained music therapists; and it has taken place in nursing homes and community settings [8]. We have a volunteer music therapist as part of our multidisciplinary team in the acute geriatric assessment ward in a general hospital in the United Kingdom [9]. Our systematic literature review was designed to establish whether MT can reduce NPS in patients with dementia and/or delirium in general hospitals.

Copyright (c) 2017 All rights reserved.

International Association for Music \& Medicine (IAMM).

MMD $|2017| 9|4|$ Page 217 


\section{Methods}

Search strategy

We registered the review protocol with PROSPERO (CRD42015024691). We searched Medline and PsycINFO using OVIDsp and CINAHL, without language restrictions, in November 2015, including search terms for music therapy, dementia and delirium (Appendix 1). We hand-searched The British Journal of Music Therapy and contacted experts in the field. Two authors independently screened titles and/or abstracts of all results (and full texts where ambiguous) for eligibility. Reference lists of relevant reviews were examined and forward citation search was carried out for relevant articles. Disputes were resolved by discussion or with a third reviewer.

\section{Selection criteria}

1. Study Type: Published peer reviewed primary studies.

2. Study Group: Groups of at least 10 adult inpatients (>16 years old) in a general (i.e. not psychiatric) hospital with a diagnosis of dementia and/or delirium using established diagnostic criteria.

3. Study Intervention: MT delivered by a Music Therapist (defined by possession of a professional MT qualification and registered with the appropriate governing body).

4. Study Outcomes: Changes in NPS as measured by validated rating scales.
Data extraction and quality assessment

We planned to extract data on age, sex, method of recruitment, diagnostic criteria, setting, number in study, timescale, dropout rate, use of scales, intervention and results, and bias (using Cochrane risk of bias tool [10]) independently by two authors.

\section{Results}

We screened 5044 titles/abstracts and read 142 full text articles (Fig 1). We found no studies which met our inclusion criteria.

We have, therefore, performed a pragmatic narrative review of excluded studies that are useful for clinicians considering the use of music or MT in the general hospital (Table 1). Studies were excluded from the systematic review for one or more of 4 reasons: not employing a music therapist, not including dementia/delirium, not performing in a general hospital, not being a primary study.

In this pragmatic narrative review, we describe studies from each group: 1) not $\mathrm{MT}[11,12]$; 2) not including dementia/delirium $[13,14]$; 3) not in a general hospital [1518]; 4) review articles (not a primary study) [4, 19]. Table 2 summarizes the results from these.

Figure 1: PRISMA flow chart

Selection of studies of music therapy for neuropsychiatric symptoms in adults with dementia and/or delirium in a general hospital

Records identified through database searching

Medline $n=896$, PsycINFO n=1011, CINAHL n=3642

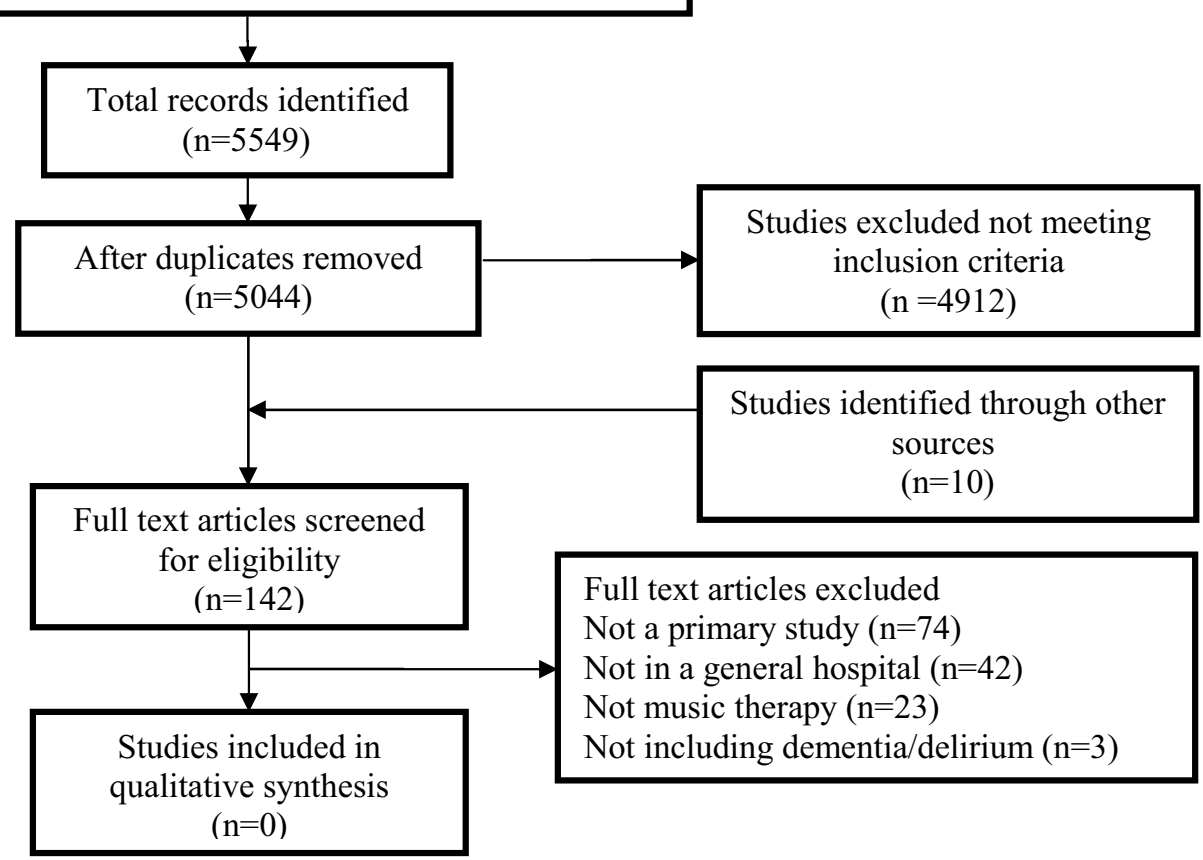


Table 1: Descriptive information of primary studies discussed in narrative review

\begin{tabular}{|c|c|c|c|c|c|c|}
\hline Study & Country & Study design & Setting & $\begin{array}{l}\text { Main reason for } \\
\text { exclusion from } \\
\text { systematic review }\end{array}$ & $\begin{array}{l}\text { Subjects } \\
\text { (intervention } \\
\text { control) } \\
\end{array}$ & Intervention \\
\hline $\begin{array}{l}\text { McCaffrey } \\
(2009)\end{array}$ & USA & RCT & $\begin{array}{l}\text { Surgical ward in general } \\
\text { hospital }\end{array}$ & No music therapist & $11 / 11$ & $\begin{array}{l}\text { Minimum } 4 \text { times daily for } 3 \\
\text { days post operatively } \\
1 \text { hour } \\
\text { Music listening (CD patient } \\
\text { choice from researcher } \\
\text { selection) }\end{array}$ \\
\hline $\begin{array}{l}\text { Helmes } \\
(2006)\end{array}$ & Canada & Single case studies & General hospital & No music therapist & $\begin{array}{l}9 \text { total } \\
(\text { self-control) } \\
7=\text { dementia } \\
2=\text { acute } \\
\text { confusion }\end{array}$ & $\begin{array}{l}\text { Mean } 5.6 \text { episodes } \\
30 \text { minutes } \\
\text { Music listening (Baroque } \\
\text { music CD researcher choice) }\end{array}$ \\
\hline $\begin{array}{l}\text { Moss } \\
(2003)\end{array}$ & UK & Observational study & $\begin{array}{l}\text { Rehabilitation unit (medicine } \\
\text { of the elderly) }\end{array}$ & $\begin{array}{l}\text { No dementia/ } \\
\text { delirium diagnosis }\end{array}$ & $14^{*}$ (no control) & $\begin{array}{l}\text { Weekly sessions for } 12 \text { weeks } \\
\text { Individual or group MT (no } \\
\text { details) } \\
\text { Singing group }\end{array}$ \\
\hline $\begin{array}{l}\text { Lin } \\
(2011)\end{array}$ & Taiwan & RCT & $\begin{array}{l}\text { Surgical ward in general } \\
\text { hospital }\end{array}$ & $\begin{array}{l}\text { No dementia/ } \\
\text { delirium diagnosis }\end{array}$ & $30 / 30$ & $\begin{array}{l}\text { Minimum four times pre and } \\
\text { post-surgery } \\
30 \text { minutes } \\
\text { Music listening (own choice } \\
\text { of CD) }\end{array}$ \\
\hline $\begin{array}{l}\text { Raglio } \\
(2008)\end{array}$ & Italy & RCT & 3 nursing homes & Not general hospital & $\begin{array}{l}30 / 29 \\
\text { Dementia } \\
\text { (mean MMSE } \\
\text { 10) }\end{array}$ & $\begin{array}{l}30 \text { minutes } \\
16 \text { weeks from MT (unclear } \\
\text { if group or individual) } \\
\text { Total } 30 \text { sessions }\end{array}$ \\
\hline $\begin{array}{l}\text { Svansdottir } \\
(2006)\end{array}$ & Iceland & RCT & $\begin{array}{l}2 \text { nursing homes } \\
2 \text { psychogeriatric wards }\end{array}$ & Not general hospital & $\begin{array}{l}\text { 20/18 } \\
\text { Moderate-severe } \\
\text { dementia }\end{array}$ & $\begin{array}{l}30 \text { minutes } \\
3 \text { times weekly for } 6 \text { weeks } \\
\text { from MT } \\
3-4 \text { patients in each MT } \\
\text { session } \\
\text { Total } 18 \text { sessions }\end{array}$ \\
\hline $\begin{array}{l}\text { Hsu } \\
(2015)\end{array}$ & UK & Cluster RCT & 2 nursing homes & Not general hospital & $9 / 8$ & $\begin{array}{l}30 \text { minutes } \\
\text { Weekly for } 5 \text { months from } \\
\text { MT } \\
1: 1 \text { sessions } \\
\text { Total } 22 \text { sessions }\end{array}$ \\
\hline $\begin{array}{l}\text { Choi } \\
(2009)\end{array}$ & $\begin{array}{l}\text { South } \\
\text { Korea }\end{array}$ & CT & Dementia unit & Not general hospital & $10 / 10$ & $\begin{array}{l}50 \text { minutes } \\
3 \text { times weekly for } 5 \text { weeks } \\
\text { Total } 15 \text { sessions }\end{array}$ \\
\hline
\end{tabular}

* Observational study on 14 patients in open group, participants may have changed during the study

$\mathrm{RCT}=$ randomized controlled trial

MMSE $=$ Mini Mental State Examination (maximum score 30, score $<26$ indicates cognitive impairment)

$\mathrm{MT}=$ music therapist

$\mathrm{CD}=$ compact disc

$\mathrm{CT}=$ controlled trial 
Table 2: Results of primary studies discussed in narrative review

\begin{tabular}{|c|c|c|c|c|c|}
\hline Study & Outcome Measure & $\begin{array}{l}\text { Baseline mean } \\
\text { Intervention } \\
\text { group }\end{array}$ & $\begin{array}{l}\text { Baseline mean } \\
\text { Control group }\end{array}$ & $\begin{array}{l}\text { Outcome mean } \\
\text { Intervention } \\
\text { group }\end{array}$ & $\begin{array}{l}\text { Outcome mean } \\
\text { Control group }\end{array}$ \\
\hline McCaffrey & MMSE (Post op day 1) & 29.72 & 30 & 26.91 & 24.9 \\
\hline (2009) & NEECHAM (Post op day 1) & NR & NR & 24 & 22.5 \\
\hline $\begin{array}{l}\text { Helmes } \\
(2006)\end{array}$ & Number of disruptive episodes during observations & NR & NA & $\begin{array}{l}30-90 \% \\
\text { reduction }\end{array}$ & N/A \\
\hline $\begin{array}{l}\text { Moss } \\
(2003)\end{array}$ & Study specific Observational rating scale & NR & NA & NR & NR \\
\hline Lin & STAI & 38.1 & 43.4 & 38.2 & 40.6 \\
\hline \multirow[t]{2}{*}{ (2011) } & VAS Anxiety (Post op day 1 ) & 1.3 & 5.1 & 1.4 & 2.7 \\
\hline & VAS Pain (Post op day 1 ) & 2.3 & 6.0 & 3.0 & 5.2 \\
\hline $\begin{array}{l}\text { Raglio } \\
(2008)\end{array}$ & NPI (8/16/20 weeks) & 27.4 & 29.5 & $18.0 / 14.6 / 16.1$ & $29.1 / 27.2 / 26.8$ \\
\hline Svansdottir & BEHAVE-AD: Activity disturbance subscale (6 weeks) & 1.6 & 1.4 & 0.7 & 1.0 \\
\hline \multirow[t]{4}{*}{ (2006) } & BEHAVE-AD: Total score (6 weeks) & 5.5 & 5.4 & 4.4 & 4.7 \\
\hline & BEHAVE-AD: Activity disturbance subscale (10 weeks) & 1.6 & 1.4 & 0.8 & NR \\
\hline & BEHAVE-AD: Total score (10 weeks) & & & & \\
\hline & & 5.5 & 5.4 & 5.0 & NR \\
\hline Hsu & NPI-NH (3/5/7 months) & 17.3 & 17.5 & $10.8 / 12.3 / 8.6$ & $24.2 / 26.5 / 34.4$ \\
\hline (2015) & DCM & 0.86 & 1.44 & $1.7 / 1.8 / 1.7$ & $0.6 / 0.6 / 0.4$ \\
\hline $\begin{array}{l}\text { Choi } \\
(2009)\end{array}$ & NPI-Q (severity) & 11.1 & 9.8 & 7.9 & 10.3 \\
\hline
\end{tabular}

$\mathrm{NR}=$ not reported

$\mathrm{NA}=$ not applicable

MMSE= Mini Mental State Examination (0-30: $<26$ indicates possible cognitive impairment)

NPI= Neuropsychiatric Inventory (Total NPI score: 0-144: higher scores indicate greater frequency and severity of symptoms)

BEHAVE-AD= Behavioural Pathology in Alzheimer's Disease rating scale Part 1: Symptoms Max score: 75, Part 2: Global score/carer distress Max score:3 (higher scores indicate increasing severity of severity and distress)

NEECHAM $=$ Neelom and Champagne confusion scale (0-30: $<24$ indicates delirium)

STAI= State Trait Anxiety Inventory (State anxiety: 20-80, Trait anxiety: 20-80: higher scores indicate greater anxiety)

VAS= Visual Analogue Scale (0-10: higher scores indicate greater severity) NPI-NH= Neuropsychiatric Inventory-Nursing Home version (as NPI, but questions rephrased, completed by caregiver in institution)

DCM= Dementia Care Mapping (-5 - +5: higher scores indicate greater wellbeing)

NPI-Q= Neuropsychiatric Inventory Questionnaire (Total score 0-96: 2 components: symptom severity (excludes frequency) and carer distress

Music intervention in a general hospital (not music therapy)

Here we describe two studies $[11,12]$ that were based in a general hospital and used music but not a qualified music therapist.

McCaffrey [11] investigated the effects of music listening on acute confusion and cognitive function in 22 cognitively healthy older adults (mean age 74.5 (intervention), 75.9 (control)) following elective hip or knee surgery. Participants were randomized using slips of paper to standard care or a CD player available at the bedside set to play for a minimum of four times a day for one hour. Across three days, the mean MMSE (Mini Mental State Examination) score and NEECHAM (Neelom and Champagne) confusion scales score in the intervention group improved. Results for this cognitively normal group may not be relevant for patients with ongoing cognitive impairment. The authors did not consider the presence of dementia, delirium or post-operative cognitive decline. They did not report the final dosage of music nor blinding of researchers, and they did not consider potential confounders. No baseline NEECHAM scores were 
reported. However, the suggestion of prevention of deterioration, and the lack of dropouts mean that this intervention was acceptable to postoperative patients and that music delivery, albeit by $\mathrm{CD}$, was feasible in this environment.

A small $(n=9)$ non-blinded study [12] assessed the efficacy of music listening on disruptive behavior (banging and shouting) in 7 patients with dementia and two with delirium on a geriatric assessment unit and family medicine ward. All patients were observed in their private or semiprivate room, a minimum of 4 times for 30 minutes, over three successive days, while baroque music was played on a portable CD player. All patients had a reduction (non significant) in calling out or banging objects after the music intervention. Despite the limitations with this study (small sample size, lack of blinding, limited consideration of potential confounders), it demonstrates that music delivery for NPS is feasible in a general hospital.

Music as therapy in a general hospital (for patients without delirium or dementia)

Here we outline two studies $[13,14]$ that took place in a general hospital.

Moss [13] reported a 6-month service evaluation of the MT service in a Medicine for the Elderly rehabilitation unit in England. The unit had 58 beds, with 14 patients attending a MT group (mean of two sessions) that ran for 12 weeks. The prevalence of delirium and dementia is not reported. The author and a MT student observed and rated the communication and interaction of each patient in the weekly MT group. On a different day, at the same time, these patients were observed and rated in the ward day room. When the patients were in the MT group, they had higher levels of spontaneous interaction than in the day area.

The intervention was developed and reviewed by the music therapist only. There was no blinding or consideration of potential confounding factors. It can be difficult to evaluate the specific role of MT beyond occupation and distraction. This study shows that MT can be implemented in a Medicine of the Elderly rehabilitation setting and can be beneficial for communication and patient interaction.

Lin [14] investigated the effects of music on anxiety and pain in 60 cognitively normal patients (mean age 62 years) undergoing elective spinal surgery. Patients were quasirandomized (according to the day of their surgery) to either usual care or listening to their preferred music for 30 minutes on the evening before surgery, one hour before surgery and in the afternoon of the first and second post-operative days. Doctors were blinded to the recruitment process but it is unclear who collected the data. All patients received identical anaesthesia and postoperative analgesia. Pain and anxiety scores were lower pre- and post-surgery in the intervention group, as rated by a Visual Analogue Scale (VAS), but the State Trait Anxiety Inventory (STAI) scores were similar for both groups. Physiological changes are beyond the scope of this review; however, systolic and mean blood pressure measurements one hour after surgery were significantly lower in the study group. There was no assessment of dementia, delirium or postoperative cognitive decline. No true randomization took place, and blinding was not mentioned. The STAI may not be an appropriate tool for this population (older Chinese people with limited emotional expression and educational backgrounds). Despite its limitations, this study demonstrates that music can be delivered, and its effect assessed, to patients in the peri-operative period.

Music therapy for patients with dementia or delirium (not in a general hospital)

Here we present four studies [15-18] that used MT (delivered by a qualified therapist) in people with moderate to severe dementia in nursing homes.

Raglio [15] recruited 59 participants (mean MMSE 10) with proxy consent from nursing homes, providing 30 sessions (30 minutes duration) of MT versus non-music activities over 16 weeks to treat NPS. It is unclear whether these sessions were individual or group based, and also unclear as to how their activities were devised (described as "non-verbal style MT"). Eligible people were quasirandomized by alphabetical order. NPS was evaluated using the Neuropsychiatric Index (NPI). The total NPI score decreased in the experimental group and was maintained four weeks after the end of treatment with significant improvements to certain domains such as anxiety and aberrant motor activity. It is not reported whether all participants attended all 30 sessions and how often sessions occurred. Intercurrent delirium was not assessed. Randomization was poor. The study was not blinded, although the assessor was blinded to treatment allocation, and other music provision was not controlled. Despite the limitations, this study shows MT is feasible for people with severe dementia in an institutional setting.

Svansdottir [16] recruited 46 people with proxy consent from two nursing homes and two psychogeriatric wards. 38 participants attended all sessions (20 in MT group). The method of randomization was not described. The qualified music therapist played the guitar and sang songs familiar to a small group of elderly Icelanders who played instruments of their choice. At six weeks, the mean score for activity disturbance on the Behaviour Pathology in Alzheimer's Disease (BEHAVE-AD) rating scale reduced in the intervention group but not in the control group. There was a non-significant decrease in the total score for both groups. The authors reported patients had been "stable" for three weeks prior to the study, thus only a minority had severe symptoms rated by the scale. Intercurrent delirium was not considered. This study shows that group MT may be effective for some aspects of behavior, such as activity disturbance, in people with moderate to severe dementia, in an institutional setting. 
A recent study [17] assessed the feasibility of a five month MT program for nursing home residents. 17 residents (mean age 84), recruited with proxy consent, were enrolled from units within two nursing homes and randomized to the MT intervention or standard care control group. Randomization was carried out independent of the researchers by the study statistician who used random decimals, that were stratified by the nursing home. Residents in the MT group had weekly 1:1 sessions, with a qualified music therapist, which were videorecorded and shown to care staff in the intervention group. This served the purpose of educating care staff about the effects of MT. The Neuropsychiatric Inventory for Nursing Homes (NPI-NH) assessed NPS, and the Dementia Care Mapping (DCM) tool evaluated residents' emotional wellbeing and quality of care both during and at two months post intervention. NPS and wellbeing improved over time in the MT group. The authors reported that most of the residents' medication regimen remained stable. There was no comment as to whether residents needed emergency medication for agitation. Intercurrent delirium was not assessed. Despite limitations such as small sample size, poor randomization and confounders such as psychotropic use, this study suggests MT is beneficial for managing NPS and has a sustained effect. In addition, it appears to be a feasible therapy to deliver in this care setting and it seems to be acceptable to residents and staff.

The efficacy of group MT on BPSD (Behavioral and Psychological Symptoms of Dementia) in patients with dementia was evaluated in a pilot-controlled trial [18]. 20 participants were recruited, with proxy consent, from a dementia day care unit and allocated non-randomly to either the MT or usual care group. The qualified music therapist delivered sessions three times weekly for 5 weeks, to all participants. After 15 sessions, the total NPI scores for symptom severity in participants and distress in carers reduced in the MT group, with a significant reduction in agitation. It is not reported if intercurrent delirium was assessed. Although this study has limitations such as small sample size and lack of randomization, results suggest that group MT can be a valuable treatment for both patients and carers.

Review articles of music therapy in dementia or delirium (not a primary study)

Most of the studies excluded were literature reviews and clinical management recommendations. We summarize two reviews $[4,19]$ of MT in the community.

A Cochrane systematic review [4] evaluated MT as a treatment for cognitive, behavioural, social and emotional problems of 396 older people with mild to severe dementia in ten randomized controlled trials (RCTs). It is uncertain whether intercurrent delirium was considered. Eight studies were set in nursing homes. MT did not always involve a qualified music therapist. There was insufficient evidence to provide a recommendation about efficacy of $\mathrm{MT}$ as a treatment for NPS in dementia due to small sample sizes, poor randomization and statistical analysis, and varying outcomes. The authors recommended that future studies use better methodology and that trial reporting conforms to standard guidelines (Consolidated Standards of Reporting Trials). Studies to compare different types of MT and to compare MT with music listening are needed.

A more recent systematic review [19] evaluated the effects of music as therapy for BPSD in mild to severe dementia of all types. 20 studies (10 RCTs and 10 non-randomized trials) with a total of 651 participants were included, 4 of which were cited in the Cochrane review [4]. Ten studies took place in nursing and residential homes. Six studies were from Japan but the setting is unclear in 4 of these articles. Assessment for intercurrent delirium was not reported. "MT" included a wide range of interventions with clinicians such as occupational therapists and nurses, which meant that they were not always administered by a qualified music therapist. MT had a moderate effect on anxiety (8 studies, $\mathrm{n}=258$ : SMD $-0.64, \mathrm{p}=0.002$ ), a small effect on behaviour (11 studies, $\mathrm{n}=397$ : SMD $-0.49, \mathrm{p}=0.003$ ), and no effect on depression (8 studies, $\mathrm{n}=250$ : SMD -0.32, $\mathrm{p}=0.08$ ). Four types of music intervention (singing, listening, improvising and rhythmic exercising) were included, but there was insufficient evidence to favor any one intervention. Once again, included studies were small, heterogeneous and of varying methodological quality.

\section{Discussion}

We performed a systematic literature review of MT for NPS in patients with dementia and/or delirium in a general hospital, using comprehensive and inclusive search terms to cover medical, nursing and social science literature. We could not identify any studies of MT for NPS in dementia and/or delirium in general hospitals.

Rather than reporting a null result, we considered studies that were excluded from the systematic review and summarized those that are relevant for the design of future studies of MT for NPS in dementia and/or delirium in a general hospital.

The majority of studies reported the use of MT in long term care settings such as nursing homes. The studies suggest that MT may be beneficial for reducing NPS in patients with dementia. In a typical general hospital, $25 \%$ of the beds are occupied by patients with dementia, who are likely to have longer stays than those without dementia [20]. With nonpharmacological approaches for NPS favored, there is a need for robust assessment of MT and provision where appropriate. MT has been shown to reduce anxiety and pain in surgical patients, and therefore it shows promise for other specialties within the general hospital. MT appears to be acceptable to 
both patients and care staff, which make this therapy promising to consider for use in the general hospital. Music delivery by passive listening, as well as formal MT, is feasible in a general hospital and for people with moderate to severe dementia.

Despite the positive findings in the studies presented, there were a number of limitations.

The studies were generally very small. Randomization and blinding were not consistently applied or described, and there was little consideration of the role of bias. The presence of delirium was rarely considered. MT often did not mean the inclusion of a qualified music therapist but passive music listening, e.g. music CDs. Exposure to music in control groups was not reported. Number and duration of "MT" sessions were variable, as was the timing of outcome measures. We searched the literature using terms for 'dementia' and 'delirium' and synonyms using a comprehensive search strategy. We do not discuss how these diagnoses were made, and are aware that the formal coding of these conditions varies; e.g. ICD-10-CM [2] uses dementia and delirium, whereas DSM-5 [21] uses the term major neurocognitive disorder for dementia.

We found a number of reviews considering the role of music delivered without a music therapist $[4,8,19]$. The reviews all conclude that the studies are small, use varying methodology, and apply a wide range of musical interventions. There is no conclusive evidence of music's effectiveness at treating NPS in any setting.

The evaluation of complex interventions requires careful design [22], particularly in interventions such as MT where therapeutic benefit relies on a positive interpersonal relationship. Researchers should clearly identify the intervention and the outcome measures to be used. Outcome measures should include validated scales for cognition, behaviour and anxiety, and assessment should take place at baseline and follow up. Prior cognitive ability, trait anxiety and depression should be taken into account. Physiological measures and neuroimaging should be considered.

The main limitation of our systematic literature review is that it yielded no studies that fit the inclusion criteria, despite utilizing comprehensive search terms and three databases. This review was designed to report the published evidence on MT in the acute hospital, so a range of relevant literature from other settings was not identified. We may have missed foreign language articles, though our initial search did not have language restrictions. Our search yielded one Japanese paper [23] (with no English abstract), but we were unable to ascertain if it would be eligible for inclusion. On examination of Ueda et al [18], we became aware of possibly relevant studies from a Japanese database that we could not access [2427]. Furthermore, grey literature may have been missed.

Following completion of our search, one study [28] was published that met our search criteria. 25 patients with dementia and/or delirium (mean MMSE 6, SD 5.4) on an acute geriatric unit were given MT from a qualified music therapist. Patients acted as their own controls over the threeday intervention period when MT was administered on day two and three. No control activity was performed. 30 minute observations were taken before, during and after MT. Assessors were not blinded. MT sessions lasted 30 minutes. Scores on validated scales of mood and engagement improved during MT. However, no baseline or long term scores were reported, and the order of control and MT was identical in all patients.

Our narrative review includes only a small number of studies from each of the excluded categories, selected as illustrative examples. There are many additional studies of music in other settings such as psychiatric hospitals and in numerous books and case studies. A recent systematic review [29] of MT for acute adult psychiatric inpatients did not identify any clearly defined model for MT delivery. There is a need to expand training for people delivering music or MT in the general hospital to identify delirium and dementia, and there is a real need for robust research to establish the most MT appropriate interventions for different patient groups in a range of settings.

\section{Conclusion}

There is no published evidence for the use of MT for the treatment of dementia and/or delirium in the general hospital setting. However, music delivery is feasible in this environment. MT may have a positive effect on NPS in dementia and in reducing anxiety and pain related to surgery. Well-designed randomized controlled trials of this complex intervention are needed.

\section{References}

1. Faculty of Old Age Psychiatry. Who cares wins: Improving the outcome for older people admitted to the general hospital: Guidelines for the development of Liaison Mental Health Services for older people. London: The Royal College of Psychiatrists; 2005.

2. Centers for Disease Control and Prevention. International Classification of Diseases, Tenth Revision, Clinical Modification (ICD-10-CM). Available at: http://www.cdc.gov/nchs/icd/icd $10 \mathrm{~cm} . h t m$. Accessed March 23, 2017.

3. National Institute for Health and Clinical Excellence and Social Care Institute for Clinical Excellence. Dementia: supporting people with dementia and their carers in health and social care. NICE clinical guideline 42. 2006. Available at:

https://www.nice.org.uk/guidance/cg42. Accessed January 25, 2017.

4. Vink AC, Bruinsma MS, Scholten, RJPM. Music therapy for people with dementia. Cochrane Database Syst Rev 2003; 4: CD003477. Available at:

http://onlinelibrary.wiley.com/doi/10.1002/14651858.CD003477.pub2/ pdf. Accessed June 18, 2016.

5. Chanda ML, Levitin DJ. The neurochemistry of music. Trends cogn sci 2013: 17(4): 179-193. 
6. World Federation of Music Therapy. About WFMT; 2011. Available at: http://www.wfmt.info/wfmt-new-home/about-wfmt/. Accessed June 23, 2016.

7. Lin S, Yang P, LaiC,et al. Mental health implications of music: Insight from neuroscientific and clinical studies. Harv Rev Psychiatry 2011; 19(1): 34-46.

8. Särkämö T, Laitinen $S$, Tervaniemi $M$, Numminen A, Kurki $M$, Rantanen P. Music, emotion, and dementia: Insight from neuroscientific and clinical research. Music Med 2012; 4(3): 153-162.

9. Mathews, J. The possibilities for music therapy in the acute geriatric medicine ward in a major teaching hospital. Leading Note June 2016; British Association for Music Therapy: London.

10. Higgins JPT, Green S (editors). Cochrane Handbook for Systematic Reviews of Interventions Version 5.1.0 [updated March 2011] The Cochrane Collaboration; 2011. Available at: http://handbook.cochrane.org/. Accessed June 23, 2016.

11. McCaffrey R. The effect of music on acute confusion in older adults after hip or knee surgery. Appl Nurs Res 2009; 22: 107-112.

12. Helmes E, Wiancko DC. Effects of music in reducing disruptive behavior in a general hospital. J Am Psychiatr Nurses Assoc 2006; 12(1): 37-44.

13. Moss H. Service evaluation: music therapy and medicine for the elderly. British Journal of Music Therapy 2003; 17(2): 76-89.

14. Lin PC, Lin ML, Huang LC, Hsu HC and Lin CC. Music therapy for patients receiving spine surgery. J Clin Nurs 2011; 20: 960-968.

15. Raglio A, Bellelli G, Traficante D, et al. Efficacy of music therapy in the treatment of behavioral and psychiatric symptoms of dementia. Alzheimer Dis Assoc Disord 2008; 22(2): 158-62.

16. Svansdottir HB, Snaedal J. Music therapy in moderate and severe dementia of Alzheimer's type: a case-control study. Int Psychogeriatr 2006; 18(4): 613-21.

17. Hsu MH, Flowerdew R, Parker M, Fachner J, Odell-Miller H. Individual music therapy for managing neuropsychiatric symptoms for people with dementia and their carers: a cluster randomised controlled feasibility study. BMC Geriatr 2015; 15:84.

18. Choi AN, Lee MS, Cheong KJ, Lee JS. Effects of group music intervention on behavioural and psychological symptoms in patients with dementia: a pilot controlled trial. Int J Neurosci 2009; 119: 471481.

19. Ueda T, Suzukamo Y, Sato M, Izumi S. Effects of music therapy on behavioral and psychological symptoms of dementia: a systematic review and meta-analysis. Ageing Res Rev 2013; 12(2): 628-41.

20. Boaden A. Fix dementia care: hospitals. Alzheimer's Society. 2016. Available at: https://www.alzheimers.org.uk/site/scripts/download_info.php?fileID= 2907. Accessed January 15, 2017.

21. American, Psychiatric Association. Diagnostic and Statistical Manual of Mental Disorders $\left(D S M-5^{\oplus}\right) 5^{\text {th }}$ ed. Washington DC: American Psychiatric Publishing; 2013. Available at: https://ebookcentral.proquest.com/lib/ed/detail.action?docID $=1811753$ . Accessed March 23, 2017.

22. Moore G, Audrey S, Barker M, et al. Process evaluation of complex interventions. Medical Research Council guidance London: MRC Population Health Science Research Network; 2014. Available at: https://www.mrc.ac.uk/documents/pdf/mrc-phsrn-process-evaluationguidance-final/. Accessed June 23, 2016.

23. Sakata A. Assisting disabled elderly people to live to the best of their abilities: Music therapy for the elderly with dementia at Belland General Hospital in Osaka. Kango 1992: 44(2): 37-46.

24. Goka F. The effects of combined music and reminiscence therapy for small groups of the elderly with senile dementia of Alzheimer Type, and the efficacy of the evaluation method. Japanese Journal of Music Therapy 2005; 5: 25-38.
25. Ikeda M, Suzuki M, Sawai D, Noda S, Ota H, Yoshimizu C. Effects of nursing intervention using rhythmic exercise for patients with severe senile dementia. Nursing Research 2006; 39(4): 301-313.

26. Mihara B, Hosoya M, Mihara Y, Fujimoto M. The effect of music therapy for elderly with dementia: a comparative study between large group and small group sessions. Japanese Journal of Music Therapy 2004; 4: 208-216.

27. Miura H, Kanayama Y, Mogi N, Endo H. Effect and significance of music therapy on elderly persons with mild dementia. Japanese Journal of Music Therapy 2005; 5: 48-57.

28. Cheong CY, Tan JA, Foong, YI, Koh HM, Chen DZ, Tan JJ, et al. Creative music therapy in an acute care setting for older patients with delirium and dementia. Dement Geriatr Cogn Dis Extra 2016; 6(2): 26875 .

29. Carr C, Odell-Miller H, Priebe S. A systematic review of music therapy practice and outcomes with acute adult psychiatric in-patients. PLoSONE 2013; 8(8):e70252.

\section{Biographical Statements}

Carol-Anne Sherriff BSc (Hons) MBChB, is a specialty trainee in old age psychiatry in South East Scotland.

Jillian Mathews BSc (Hons), PGCE, MSc, MSc, is a UK registered creative music therapist, who specialises working with the elderly and dementia in the general hospital setting.

Emma L. Reynish MBBCh, MD, FRCP, is a Professor of Dementia Research at Stirling University and Consultant in Medicine of the Elderly in NHS Lothian.

Susan D. Shenkin BSc (Hons), MBChB, MSc, MD, FRCP (Edin), is a Clinical Senior Lecturer in Geriatric Medicine at the University of Edinburgh, and Consultant in Medicine of the Elderly in NHS Lothian. 


\section{Appendix 1.}

\section{CINAHL}

S1 (MH "Dementia+")

S2 TX dement*

S3 TX alzheimer*

S4 TX lewy n2 bod*

S5 TX chronic $n 2$ cerebrovascular

S6 TX "organic brain disease * OR TX "organic brain synd\$3̋hne ${ }^{* T X}$ "toxic psychosis"

S7 TX "normal pressure hydrocephalus" AND TX shunt*

S8 TX "benign senescent forget ${ }^{*}$

S9 TX cerebr* $\mathrm{n} 2$ deteriorat*

S10 TX cerebr $\mathrm{n} 2$ insufficien*

S11 TX pick n2 disease*

S12 creutzfeldt* OR jcd OR cjd

S13 TX korsako*

S14 TX binswanger*

S15 TX huntington*

S16 TX cognitive n2 impair*

S17 delirium

S18 (MH "Delirium") OR (MH "Delusions+")

S19 TX deliri*

S20 TX deleri*

S21 TX "acute confusion"

S22 TX "acute organic psychosyndrome"

S23 TX "acute organic psychosyndrome"

S24 acute organic psychosyndrome

S25 TX "Wernicke encephalopathy"
S26 TX encephal*

S27 acute psycho-organic syndrome

S28 TX "clouded state"

S29 TX "clouding of conscious*"

S30 exogenous psychosis

S32 TX "toxic confus*"

S33 TX "acute confusional state" S1 OR S2 OR S3 OR S4 OR S5 OR S6 OR S7 OR S8 OR S9 OR S 15 OR S 16 OR S 17 OR S 18 OR S 19 OR S 20 OR S 21

S34 OR S27 OR S28 OR S29 OR S30 OR S 31 OR S32 OR S33

S35 (MH "Music Therapy")

S36 TX music*

S37 TX sings OR TX singing

S38 TX "auditory stimul*"

S39 TX song* OR TX melody OR melodic

S40 (MH "Music")

S41 S35 OR S36 OR S37 OR S38 OR S39 OR S40

S42 S34 AND S41

S43 (MH "Randomized Controlled Trials")

S44 (MH "Clinical Trials+")

S45 TX randomized OR TX randomised OR TX clinical trial C

S46 S43 OR S44 OR S45

S47 S42 AND S46 


\section{MEDLINE}

1. exp dementia/

2. dement*.mp.

3. alzheimer ${ }^{\star} \cdot \mathrm{mp}$.

4. $\left(\right.$ lewy $^{\star}$ adj2 bod $\left.{ }^{\star}\right) \cdot \mathrm{mp}$.

5. (chronic adj2 cerebrovascular).mp.

6. ("organic brain disease" or "organic brain syndrome").mp.

7. ("normal pressure hydrocephalus" and "shunt").mp.

8. "benign senescent forgetfulness".mp.

9. $\left(\right.$ cerebr $^{\star}$ adj2 deteriorat $\left.{ }^{*}\right) \cdot \mathrm{mp}$.

10. $\left(\right.$ cerebr $^{\star}$ adj2 insufficien $\left.{ }^{\star}\right) \cdot m p$.

11. (pick ${ }^{\star}$ adj2 disease).mp.

12. (creutzfeldt or jcd or cjd).mp.

13. huntington*.mp.

14. binswanger*.mp.

15. korsako*.mp.

16. "cognitive impairment".mp.

17. or/1-16

18. exp delirium/

19. deliri*.mp.

20. deleri*.mp.

21. "acute confusion".mp.

22. "acute organic psychosyndrome".mp.

23. "Wernicke encephalopathy".mp.

24. encephal*.mp.

25. "acute psycho-organic syndrome".mp.

26. "clouded state".mp.

27. "clouding of consciousness".mp.

28. "exogenous psychosis".mp.

29. "toxic psychosis".mp.

30. "toxic confusion".mp.

31. "acute confusional state".mp.

32. or $/ 18-31$

33. exp music therapy/

34. exp music/

35. music $^{\star} . \mathrm{mp}$.

36. $\operatorname{melod}^{\star} \cdot \mathrm{mp}$.

37. auditory stimul*.mp.

38. singing/or song*.mp.

39. (sings or singing).mp.

40. or/33-39

41.17 or 32

42.41 and 40

\section{PsycINFO}

1. exp dementia/

2. dement ${ }^{\star} \cdot \mathrm{mp}$.

3. alzheimer*.mp.

4. $\left(\right.$ lewy $^{\star}$ adj2 bod $\left.{ }^{\star}\right) \cdot m p$.

5. (chronic adj2 cerebrovascular).mp.

6. ("organic brain disease" or "organic brain syndrome").mp.

7. ("normal pressure hydrocephalus" and "shunt").mp.

8. "benign senescent forgetfulness".mp.

9. $\left(\right.$ cerebr $^{\star}$ adj2 deteriorat $\left.{ }^{\star}\right)$.mp.

10. (cerebr $^{\star}$ adj2 insufficien $\left.{ }^{\star}\right) \cdot \mathrm{mp}$.

11. (pick ${ }^{\star}$ adj2 disease).mp.

12. (creutzfeldt or jcd or cjd).mp.

13. huntington ${ }^{\star} . \mathrm{mp}$.

14. binswanger ${ }^{\star} \cdot \mathrm{mp}$.

15. korsako*.mp.

16. "cognitive impairment".mp.

17. or/1-16

18. exp delirium/

19. deliri*.mp.

20. deleri*.mp.

21. "acute confusion".mp.

22. "acute organic psychosyndrome".mp.

23. "Wernicke encephalopathy".mp.

24. encephal*.mp.

25. "acute psycho-organic syndrome".mp.

26. "clouded state".mp.

27. "clouding of consciousness".mp.

28. "exogenous psychosis".mp.

29. "toxic psychosis".mp.

30. "toxic confusion".mp.

31. "acute confusional state".mp.

32. or/18-31

33. exp music therapy/

34. exp music/

35. music $^{\star} . \mathrm{mp}$.

36. $\operatorname{melod}^{\star} \cdot \mathrm{mp}$.

37. auditory stimul ${ }^{\star} . \mathrm{mp}$.

38. singing/or song ${ }^{\star} . \mathrm{mp}$.

39. ( sings or singing).mp.

40. or/33-39

41.17 or 32

42. 41 and 40 